\title{
Out of sight but not out of mind: California refocuses on groundwater
}

\author{
Thomas Harter, UC Cooperative Extension Specialist, Department of Land, \\ Air and Water Resources, UC Davis \\ Helen E. Dahlke, Assistant Professor, Department of Land, Air and Water \\ Resources, UC Davis
}

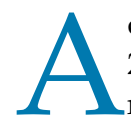
deepening 3-year drought, accentuated by a record dry 2013, has focused public attention on groundwater like never before. And for a good reason: Almost everywhere in California, groundwater levels have been drawn to record depth and domestic and farm wells are drying up at an unprecedented pace. Well drillers are booked for months in advance to deepen existing wells or to construct new, much deeper ones. Even in a wet year, groundwater makes up one-third of our urban and agricultural water supply, but in 2014, as in previous dry years, nearly two-thirds of the state's water supply will be pumped from wells that are tapping into California aquifers. The economic consequences of not having this hidden resource available in future droughts would be catastrophic.

\section{A significant number of regions in California won't have groundwater available in another generation or two if we continue business as usual.}

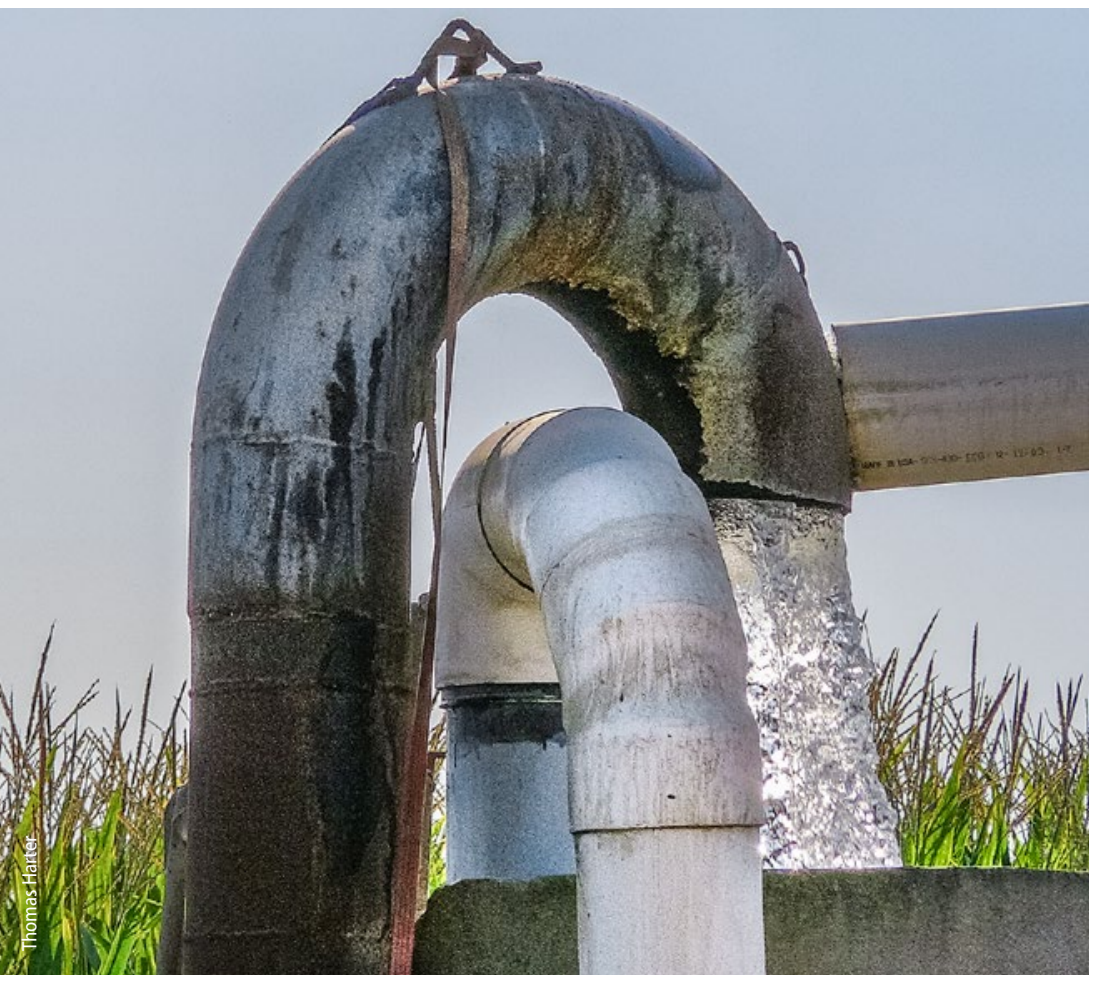

Kings County well pumping into an irrigation system.
Yet, a significant number of regions in the state will not have this resource available in another generation or two if we continue business as usual. As groundwater depletes, damage will increase to our water, transportation and urban infrastructure due to land subsidence; critical ecosystems in groundwaterdependent streams will be lost; and costs will incur from pumping irrigation water from deepening water levels and preventing seawater intrusion into our coastal aquifer systems.

The state has seen similar crises before, particularly in Southern California, where groundwater basins are smaller, have more limited supplies, and had been overtapped soon after powerful turbine pumps were invented in the early 20th century. Extended, expensive court battles between thirsty urban neighbors have divided up the basins and resulted in adjudications that allocate specific amounts of water to specific groundwater users. The adjudications are administered through a local water master and have halted, if not reversed, the overdraft of these basins. A wide range of measures and complex arrangements between multiple stakeholders and the public have generated significant water conservation, development of alternative surface water supplies, and increased groundwater recharge and groundwater banking opportunities.

In other regions of California, particularly in the Central Valley, groundwater overdraft continues, exacerbated by belowaverage, or well-below-average, precipitation in 6 of the past 8 years. In some areas, including Paso Robles and the eastern San Joaquin Valley, overdraft is a recent phenomenon caused by agriculture expanding into former rangelands and growers using either stream-fed flood and furrow irrigation or high-efficiency irrigation systems that rely on groundwater that lacks recharge from streams.

Past droughts have provoked calls for groundwater action: In 1992, the California Legislature passed AB 3030, which encouraged local agencies to collaborate and develop groundwater management plans, though few guidelines were provided. Following another drought, the Legislature passed SB 1938 in 2002, which required those local agencies receiving state funding for water projects to have a groundwater management plan in place. This time, the state provided guidelines on minimum standards that the plans needed to fulfill to receive a passing grade from the state's Department of Water Resources (DWR). Following the 2007-2009 drought, the Legislature asked DWR to develop more rigorous groundwater level monitoring throughout the state, with the support of local agencies or initiatives.

Significant improvements in groundwater management occurred in some areas. Local agencies began thinking and talking about managing their groundwater; education and outreach activities have been offered to stakeholders through various organizations, including UC Cooperative Extension; and local advisory groups have engaged the public and the many local and regional agencies dealing with or affecting groundwater. 
However, because none of this has stopped groundwater overdraft where it occurs, the demand for more comprehensive groundwater management has grown significantly over the past year. Last fall, the State Water Board (SWB) introduced a discussion draft of a groundwater work plan, and, in February, Governor Brown issued the Water Action Plan, which calls for significant legislative action on groundwater management. In response, the Association of California Water Agencies and a broad group involved in the stakeholder-driven process facilitated by the California Water Foundation issued these proposals, which indicate broad consensus on critical elements of groundwater management:

- Groundwater is most effectively managed at the local or regional basin level, with support from the state.

- Local groundwater management entities must be given better tools, such as clear mandates to assess, measure, monitor and allocate their groundwater and control its extraction.

- The definition of groundwater sustainability can be set at the state level and translated into specific actionable thresholds that must be enforced locally, with a credible threat of state enforcement should the local efforts be unsuccessful.

- Much better data collection, analysis, reporting and data integration are needed to provide transparency, to support local management efforts and to properly inform the public. This requires much stronger planning and support within the DWR and SWB.

But more needs to be done. Local land-use decisions on urban and agricultural development, which have critical impacts on groundwater resources, must be consistent with groundwater management objectives. This will require significant communication between land-use and groundwater managers. Effective integration with water quality management and surface water management efforts, which are governed separately, is also required. And none of these efforts can occur without sustained funding through a mix of local and state sources.

\section{Can agricultural fields aid in water security?}

Of particular interest to UC is the emphasis on the need for new tools to better manage groundwater. In 2014, a team of UC Davis faculty and Cooperative Extension specialists and advisors began exploring the feasibility of using agricultural land for transferring excess surface water during the winter rainy season into groundwater aquifers. The project is called Groundwater Banking: An Agricultural Systems Approach for Water Security. The idea is that during storms (or flood control releases) excess surface water could be directed from streams via existing water conveyance systems onto dormant agricultural fields, which would then serve as infiltration basins. If successful, several hundred or thousand acre-feet of water could be recharged annually into California's aquifers during very short periods. The banked groundwater could then be used to satisfy agricultural and urban water demand during dry years, leaving the available surface water for critical environmental uses such as enhanced streamflow.

This 3-year project, funded by UC Division of Agriculture and Natural Resources, aims to set up pilot groundwater recharge

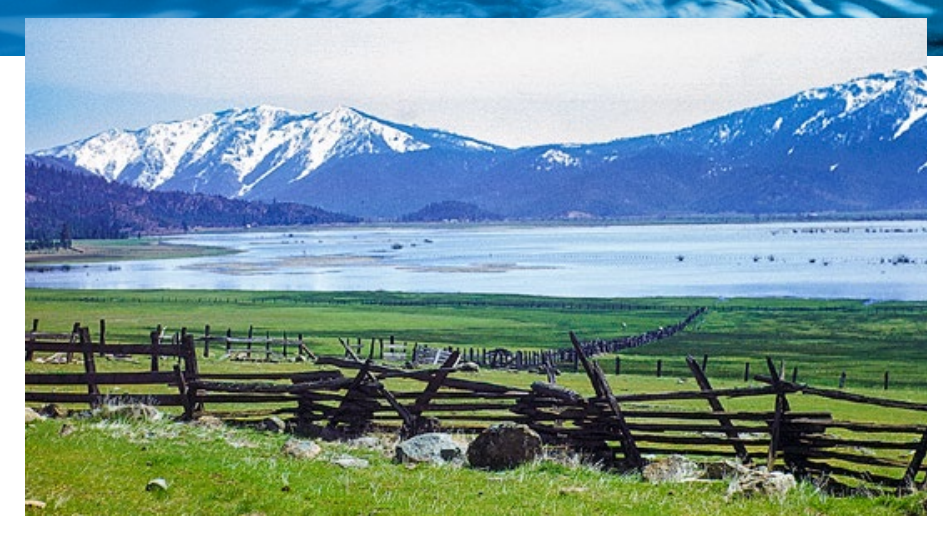

field experiments, which would provide valuable data to address concerns about the costs and risks to crops, the influence these projects may have on groundwater levels and flows, and the possibility of recharging contaminated water or degrading groundwater quality by leaching contaminants such as nitrate from the vadose zone. Potential collaborators for the field experiments include the Glenn County Water Advisory Committee and the Bureau of Reclamation.

Besides the field experiments, the project is also developing suitability indices, such as the Soil Agricultural Groundwater Banking Index (SAGBI), to identify optimal recharge sites on agricultural land. Developed by Toby O'Geen, UC Cooperative Extension soil resources specialist, and the UC Davis Soil Resource Laboratory, the SAGBI ranks soils most suitable for groundwater recharge based on their ability to accommodate deep percolation, maintain a freely drained root zone, distribute water evenly on the landscape, minimize groundwater contamination by salts, and resist erosion and soil crust formation. This index will be combined with information on each possible site's climate, geology, irrigation infrastructure, soil water quality and surface and subsurface hydrology. If repeatedly used for groundwater recharge, a site would need to be protected from high application rates of fertilizer and pesticides; hence, the research team is investigating land with cropping systems that demand low nutrient and pesticide input, such as alfalfa fields and irrigated pasture. Recharge on fields with low-nutrient input cropping systems could sustain or even improve groundwater quality in areas where buildup of nutrients, pesticides, pollutants and salt in the soil is otherwise a concern.

A further aspect of the project is to develop knowledge of the socioeconomic effect of groundwater recharge on agricultural production, farm revenues and crop yields, all of which are fundamental factors in whether the groundwater banking program might be adopted across California. Data collected could serve as a foundation for developing economic incentives at the local, state or federal level to acknowledge the landowner's service to the local community and California's water supply reliability.

The 2013 update of the California Water Plan states that "one of the roles and goals of California is to seek statewide water supply reliability and sustainability [and] to strive for sustainable groundwater supplies throughout the state." Enhancing groundwater storage through intentional agricultural groundwater banking could potentially provide a means to attain these goals. Groundwater is California's largest source of water during droughts, and UC's research on its management, recharge and conjunctive use aims to ensure that a reliable supply is secured for farms and cities throughout the state. 